\title{
Regional policy mixes for enterprise and innovation: A fuzzy-set clustering approach
}

Environment and Planning C: Politics and Space

0 (0) $1-19$

(C) The Author(s) 2017

Reprints and permissions: sagepub.co.uk/journalsPermissions.nav DOI: 10.1 I77/23996544I769I5I5 journals.sagepub.com/home/epc

\section{Annalisa Caloffi}

University of Padova, Italy

\section{Marco Mariani}

IRPET-Regional Institute for the Economic Planning of Tuscany, Italy

\begin{abstract}
The paper identifies different regional policy mixes, ranging from the more minimal to the more proactive or entrepreneurial and verifies their diffusion in the Italian regional enterprise and innovation policies. The empirical analysis is based on an original database containing every enterprise and innovation programme that has been implemented in Italy from 2007 to 2013, and is carried out by means of fuzzy-set clustering techniques. The results show the existence of remarkable heterogeneity, partly reflecting the well-known North-South divide, with some regions adopting minimal policy mixes and other regions adopting different types of proactive mixes.
\end{abstract}

\section{Keywords}

Policy mix, enterprise and innovation policy, regional policy

\section{Introduction}

The recent years have witnessed a revival of public debate on industrial policy (Mazzucato, 2013; Stiglitz and Lin, 2013); an issue that has always opposed the supporters of the minimal state to the advocates of a proactive intervention (Chang, 2002; Pack and Saggi, 2006; Peck et al., 2012; Weiss, 1998). However, even assuming that industrial policy is useful to promote private investments and innovation, another matter of debate is what policies should be adopted in the presence of scarce resources.

Different schools of thought can provide different answers to this problem (Laranja et al., 2008), and these theoretical rationales can have an influence on public decision makers. However, policymakers' choices in the field of enterprise and innovation policy often depend on a large number of interplaying factors, which are at least as relevant as theoretical rationales (Laranja et al., 2008; Majone, 1989). These factors may

\section{Corresponding author:}

Annalisa Caloffi, Department of Economics and Management, University of Padova, via del Santo, 33, Padova 35I23, Italy. Email: annalisa.caloffi@unipd.it 
include: the legal and institutional framework; the type and role of economic and electoral coalitions and the public opinion; the political belief of policymakers; the vision of development the latter have in mind for the territory they govern and their knowledge of its actual potential; the legacy of past policies and the influence of policy models adopted elsewhere; the structure of the economy and its level of innovativeness (Bressers and O'Toole, 1998; Campbell, 1998; Jones, 2001; McCann and Ward, 2013; Painter, 2005). Choices might also be influenced by the quality of government (Rodríguez-Pose and Garcilazo, 2015). Moreover, it should be borne in mind that policies may emerge from multi-actor, multi-level decision contexts (Flanagan et al., 2011; Howlett and del Rio, 2015; Lanahan and Feldman, 2015; Laranja et al., 2008; Magro and Wilson, 2013; Matti et al., 2016).

The results of this complex decision making have been investigated by a literature that has paid attention to the process of policy instrument choice and on the resulting policy mixes (Flanagan et al., 2011; Howlett, 1991, 2004). While much of this literature has focussed on national policymakers, Laranja et al. (2008) define a number of ideal-typical regional policy mixes that can be consistent with different theoretical approaches to innovation.

Drawing on this contribution, as well as on the policy instrument choice and the regional policy literatures, we put forward a novel empirical application of the concept of regional policy mix. ${ }^{1}$ We refer to the policy mix as a combination of policy objectives, instruments (Branscomb and Florida, 1998; Flanagan et al., 2011) and operationalisation modes (Laranja et al., 2008; Linder and Peters, 1989). We apply this definition of policy mix to the systematic analysis of the enterprise and innovation policies of Italian regions, and shed light upon their heterogeneity.

The operationalisation of theoretical concepts requires some simplifications and the adoption of some degree of pragmatism. Indeed, as shown by Laranja et al. (2008), even if the theoretical approaches may offer concrete indications regarding policy, a one to one correspondence between instruments and theories hardly exists. For example, the use of firm subsidies may be compatible with more than one approach, although each of these may have its specific reason for providing the subsidy. However, the knowledge of the objectives of the programme that provides the subsidy can help interpretation. In addition, knowledge of operationalisation modes such as targeting, eligibility or selection criteria may further improve the understanding of how the instruments pursue their objectives in practice (Chiang, 1998; Eickelpasch and Fritsch, 2005; Nauwelaers and Wintjes, 2003). Drawing on this information, we are able to identify a policy mix that can be consistent with a minimal approach to industrial policy, and a policy mix that mirrors a more proactive or entrepreneurial attitude of the policymaker. Within each of the two opposing policy-mixes recalled above, we are also able to identify further internal varieties. As many existing mixes are the result of a collective process that develops over time and 'are developed without any sense of an overall conscious design' (Howlett and del Rio, 2015: 1235), we will interpret them as emergent policy strategies (Jørgensen and Mintzberg, 1987).

In our empirical analysis, all Italian regional policies for enterprises and innovation that have taken place from 2007 to 2013 are scrutinised, extracting from each programme call selected information about the objectives, the instruments and the operationalisation modes, as well as the amount of money allocated to the programme itself. Given that the policies of the Italian regions strongly rely on the availability of European Union (EU) funds, it makes sense to consider the time schedule of these funds (Brancati, 2015). Although the use of such funds from the European regions requires compliance with a number of priorities and guidelines defined at the EU level, the regions still have some discretion in setting specific objectives and forms of intervention. Since the Italian constitutional reforms implemented in 2001 (Constitutional Law n. 3/2001), the Italian regions are responsible in the area of 
enterprise and innovation policy, but devolution has not implied a complete retreat of the national government. Therefore, we also consider the presence of higher level policymakers (Flanagan et al., 2011).

A fuzzy-set cluster analysis technique is used in order to identify different policy mixes in the data and to assess to which extent regions are attributable to these mixes. In real-world policymaking, it is hard to imagine policy mixes that exactly conform to the 'minimal' or 'proactive' type, as sticking to these labels is unlikely a concern of decision makers. The reality is, of course, much more nuanced. Therefore, the use of fuzzy-set clustering is particularly appropriate for this kind of analysis, as this statistical technique allows units (regions) to belong to several clusters at the same time but with different degrees of membership.

The article proceeds as follows. The next section outlines the main theoretical foundations of industrial policies and seeks to define some simple models of intervention that can be implemented at the regional level. Then, we set the scene for the empirical analysis by briefly outlining the institutional framework of Italian regional and national industrial policy. The following sections present the data collected, describe the variables and the fuzzy-set clustering methodology applied to these variables. Finally, we report the results of the empirical analysis and discuss them in the two concluding sections of the article.

\section{Theoretical rationales and empirical regional policy mixes}

The traditional approach to industrial policy, as sketched out in Pigou (1912), and further elaborated from Samuelson (1947) onwards, derives from the understanding that market failures generate a level of private investment that is systematically lower than the socially desirable one, and thus, a sub-optimal equilibrium that could be improved by well-designed public interventions. However, when this kind of thinking combines with the typically neoliberal confidence in the self-regulating ability of the market (forming an 'unholy' alliance, Chang, 2002), the main suggestion is to avoid market distortions and refrain from public intervention, as any attempt to remedy market failures is potentially subject to government failures that may inhibit any welfare improvement (Haapanen et al., 2014; Pack and Saggi, 2006). This approach, which has shaped real-world industrial policies around the globe, basically relies on a-spatial policy tools that can be used indifferently whatever the level of government. Therefore, no specificity of regional policy is envisioned. ${ }^{2}$

An alternative set of popular approaches to industrial policy is motivated by the evolutionary and system-based thinking, which highlight the presence of systemic failures, or the need of systemic change, to justify policy intervention (Metcalfe, 1994; Peneder, 2016; Woolthuis et al., 2005). These approaches maintain that the role of the policymaker is that of providing opportunities for learning and technological change, also through the support to innovation systems. This main goal can be achieved by facilitating the openness to change and variety with the promotion of $R \& D$ and technology transfer activities, the achievement of a well-functioning selection environment that allows the identification of the most promising projects and relationships among system agents, and the accumulation of knowledge and capabilities (Dosi et al., 1988; Nelson and Winter, 1982). The various territorial innovation models (e.g., clusters, industrial districts and regional innovation systems) that rest on evolutionary grounds envisage a specific role for a regional level of government that is able to understand and to act upon the specific evolutionary mechanisms of variety, selection and retention that are embedded in the local context (Coenen et al., 2016; Lambooy and Boschma, 2001; Uyarra, 2010). This regional policymaker should play a role that extends far beyond the mere correction of market failures. Her attitude, 
which resembles that of the developmental state (Johnson, 1982) or the entrepreneurial or innovative state (Mazzucato, 2013), results into a proactive role in order to encourage growth-enhancing innovations and of the attempt to engage in a process of mutual learning with the private sector (Morgan, 2016; Rodrik, 2004) or, in the words of Foray (2015), in a process of entrepreneurial discovery.

Drawing on the previously cited streams of literature, the two extreme models of the minimal and the proactive regional government can be contrasted. In the former case, characterised by a neo-liberal flavour, the policymaker seeks to intervene in such a way as not to alter the regional economic structure and the existing system of relationships among local agents. She could privilege the use of (apparently) neutral tools such as horizontal and generic incentives delivered to single firms in an automatic or semi-automatic way, rather than on selective ones, which would imply a choice about which projects and which companies deserve support. This policymaker is not particularly willing to introduce specific targets, be they sectoral, technological or territorial, in the belief that firms, the best and brightest ones in particular, know what to do better than she does. This type of industrial policy may possibly be complemented by forms of social protection in declining industries and areas.

In the latter case, that of the proactive policymaker of evolutionary and systemic kind, the main objective is to promote structural change, help firms break the possible lock-ins in which they are trapped, and influence the direction of regional development. To do this, she could prioritise the generation of new varieties of knowledge and competencies in the local system by focussing on the support to $R \& D$ and on the diffusion of technologies that may offer the greatest opportunities for development or that produce interesting externalities (e.g., key enabling technologies (KETs)) (Lambooy and Boschma, 2001; Laranja et al., 2008). In addition, she could support the creation of intermediaries performing knowledge brokerage functions (Howells, 2006) to promote the diffusion of new knowledge in firms (Laranja et al., 2008). This policymaker could engage in a structured collaboration with the private sector to identify the most promising projects and relationships on which to concentrate efforts and extract information that could be valuable for adjustments or for the design of subsequent policies (Eickelpasch and Fritsch, 2005). The more the policymaker is sensitive to systemic issues, the more she will try to intervene on collaborations, which form the backbone of a system, rather than on individual companies (Cooke et al., 2004, OECD, 2011).

Remaining on the side of the relatively proactive policymakers, there are other intervention models that should not being forgotten, which are inspired by the more traditional logic of growth poles (Boudeville, 1966; Perroux, 1955). The basic policy idea connected to growth poles is that the settlement in a region of a firm belonging to a propulsive industry can trigger localised growth by self-reinforcing mechanisms transmitted through backward and forward linkages. This strategy was used in many European countries during the 20th century in the attempt to boost growth in depressed areas (Parr, 1999). To the extent that these policies have been the object of (partial or total) devolution to the regional governments - as, for example, has happened in Italy (Florio, 1996) - they can be considered as part of the toolbox of a proactive (although nonevolutionary) regional policymaker.

These ideal-typical policy mixes will be used in the following sections in order to uncover the heterogeneity that lies behind the generic label of regional policy.

The investigation of the reasons for such heterogeneity would require a specific analysis that goes beyond the scope of this article. However, after having uncovered the different policy mixes, we will advance some suggestions on some of these reasons, with no claim of 
completeness. We will focus on two of the various aspects we mentioned in the introduction, which can have an influence on policymakers' choices: the quality of government and the level of regional innovativeness. For both aspects, proxies are available in the literature, which may be introduced in the empirical analysis. We will do so in order to understand, in a descriptive fashion, whether more proactive policy mixes are found in regions with high quality of government and high level of innovativeness, and vice versa. There are reasons to believe that governments with a low level of effectiveness and accountability and a high level of corruption do not put a great deal of effort in generating quality institutions, such as rules to promote entrepreneurship and innovation, and public goods (Adsera et al., 2003; Giddens, 1991; North, 1990; Rodríguez-Pose and Garcilazo, 2015). ${ }^{3}$ Therefore, lowquality governments could refrain from designing specific, strategies that pursue structural change. They could rather take a less proactive and more inclusive approach of indiscriminate incentivisation that is likely to maintain the status quo and existing rentseeking positions, while higher quality governments could take a more proactive and priority-oriented approach. Moreover, policymakers operating in less innovative areas could adopt less proactive policy mixes to respond to a low demand for innovation support from regional firms, while the opposite could happen in more innovative regions (Morgan, 2007; Oughton et al., 2002).

\section{The Italian institutional context}

Since the beginning of the 2000s, the scenario of Italian industrial policies has become more complex than it used to be. In order to understand its current features, this section briefly explains the interplay of national and regional competencies in the field of industrial policy and the programming documents that allocate funds to industrial programmes.

The history of Italian industrial policies has been characterised by the presence of state interventions in strategic industries and by a vision of regional policies as tables at which large projects of local development with Perrouxian flavour were negotiated between the national government and the large industrial players available to locate their plants in the laggingbehind South (Florio, 1996; Grabas, 2014). Following the crisis of national champions, national industrial policy went through a liberal phase in the 1980s and 1990s that has seen the widespread use of a horizontal and rather indiscriminate subsidisation of firms (Rolfo and Calabrese, 2003) as well as, on the side of regional policy, the decline of a top-down approach in favour of an alternative one that recognises local governments and intermediate bodies in lagging-behind regions the right to have a stake in the process (Polverari, 2013).

With the new millennium, Italian industrial policies are being affected by two major changes. The first is the emphasis that is generally put back, at least from the early $2000 \mathrm{~s}$, on $\mathrm{R} \& \mathrm{D}$ and innovation as a result of the cultural influence of system-based thinking on policymakers (Nauwelaers and Wintjes, 2003).

Second, since the constitutional reform of 2001, all Italian regions have gained a prominent role in the design and the implementation of enterprise and innovation policies, moving from the role of policy-takers to the role of policy-shapers. The reform has introduced an institutional framework where the state has a limited number of exclusive competencies and the regions have general or 'residual' ones. According to a concurrentpowers frame, state and regions share a broad number of competencies under the principle of the vertical subsidiarity. For this reason, Italy currently has a series of industrial policies that are designed and implemented by the Italian regions, as well as some programmes of national relevance that are managed by the national government and that can be either nationwide in their scope or targeted to specific lagging-behind areas. 
Since the regional legislative autonomy has not been accompanied by financial autonomy, the Italian regions are strongly dependent on transfers from the central government, and these transfers have been anything but growing in the last few years. As a result, a major part of today's regional policies in Italy is funded through EU structural funds. In addition to such funds, regional policies are financed through the national fund for underutilised areas (FAS) and through other national resources added to structural funds. ${ }^{4}$

A number of programming tools seek to ensure consistency between national and regional policies. With regard to the programming of EU funds, the National Strategic Reference Framework (QSN) - developed by the state and the regions - identifies a set of priorities over several years, as well as the funds (structural funds and other financial instruments) that are needed to implement such strategies. The strategy set out in the QSN is implemented through the National Operational Programmes (PONs), the Regional Operational Programmes (ROPs), the Interregional Operational Programmes and the European territorial cooperation. Some programmes are devoted to convergence regions only (Apulia, Calabria, Campania and Sicily).

We will consider the programmes that refer to convergence regions later. As for the other national policies, in recent years the government has chosen a rather proactive type of intervention that supports private R\&D and technology transfer activities and promotes the diffusion of KETs (Mariani et al., 2013; Ministero dello sviluppo economico, 2012). The main policies that have shaped this type of intervention are Industry 2015 (now dismissed), and Smart Cities and Communities and Social Innovation, with a total of four interventions that have absorbed nearly one-third of the total resources activated in the period under review. However, there are also interventions aimed at supporting generic forms of investment that still have a considerable weight (e.g., the Central Guarantee Fund).

\section{Data}

In order to analyse the choices made by the Italian regional policymakers in the area of enterprise and innovation, we have collected information on all the interventions they have implemented under the ROPs co-financed by the ERDF and, in minor part, the Regional Implementation Programmes funded by the FAS. ${ }^{5}$ For the analysis of the four convergence objective regions, we have also considered the national interventions implemented as part of the National Operational Programme Research and Competitiveness and of the Interregional Operational Programme Renewable Energy and Energy Efficiency.

We have considered the interventions actually implemented by the Italian regions over the period 2007-2013, and not those merely planned. The amount of resources devoted to implemented policies may differ both from that of the planned resources (which, for example, may never be fully activated) and from the amount actually paid to final beneficiaries of the interventions themselves (for example, some of the resources could not be delivered because of a low number of requests from potential beneficiaries, revocation or renounces). Therefore, the financial measure on which we will focus in order to weigh the different interventions is represented by the resources made available through the calls for tenders published by the end of October 2014.

A single database of all these policies does not exist. ${ }^{6}$ For this reason, we had to create one from the information gathered on the calls for tender periodically published on the official bulletins of individual Italian regions and the central State, where public administrations must publish their calls. ${ }^{7}$ From the call for tenders, we extracted information about policy goals, instruments and operationalisation modes such as final beneficiaries, eligibility conditions or technology targets. This information must be reported by law in all 
programme calls. After creating the database of policies, we constructed a number of classification variables (see the next section) on the basis of the discussion presented in the initial section of the article.

\section{Classification variables and methodology}

In order to highlight the presence of different policy mixes, each characterised by a particular combination of the observed policies, it can be appropriate to perform a cluster analysis.

The six variables we define to identify the different policy mixes through the cluster analysis are presented in Table 1 together with some descriptive statistics. The choice of variables is driven by the literature on enterprise and innovation policies, particularly at the regional level. Such choice is inevitably constrained by the relatively limited information contained in the programme calls. However, these are the only data sources that guarantee inter-regional comparability. The variables refer to the different aspects of the policy mix, and, in particular: policy goals (support of R\&D vs. generic capital investments), instruments (creation of intermediaries; set up of complex, multi-agent local development projects) and operationalisation modes (the intervention targets individual firms or collaborations; it targets-specific technologies; funds are granted after expert evaluation). ${ }^{8}$

The first variable is the ratio of funds devoted to R\&D support to the total amount of funds devoted to enterprise and innovation policies ( $R \& D$ support). This variable shows to what extent regional governments focus on structural change and regional renewal through the promotion of R\&D-related activities, be they targeting individual firms or collaborations. A low value of this variable is to be found in regions that mostly offer incentives for the implementation of generic investment projects, whatever their level of innovativeness.

The two following variables refer to policy instruments. The variable intermediaries reports the percentage of funds allocated to interventions supporting the creation of intermediaries. These organisations can have different nature (e.g., technology centres, technopoles, innovation centres) and status (private, public or mixed), but their common

Table I. Classification variables.

\begin{tabular}{lllllll}
\hline Variable & Description & Obs & Mean & Std. Dev. & Min & Max \\
\hline R\&D supports & $\begin{array}{l}\text { Pct of funds devoted to R\&D } \\
\text { support }\end{array}$ & 20 & 50.1 & 24.4 & 11.9 & 94.8 \\
Intermediaries & $\begin{array}{l}\text { Pct of funds devoted to the } \\
\text { creation of intermediaries } \\
\text { Local development }\end{array}$ & 20 & 9.4 & 12.4 & 0.0 & 33.9 \\
& $\begin{array}{l}\text { Pct of funds to large-scale, } \\
\text { usually negotiated, projects of } \\
\text { local development other than } \\
\text { university-industry }\end{array}$ & 20 & 9.6 & 16.6 & 0.0 & 53.3 \\
Collaboration & $\begin{array}{l}\text { Pct of funds devoted to support } \\
\text { university-industry } \\
\text { collaborations }\end{array}$ & 20 & 27.0 & 18.4 & 0.0 & 69.2 \\
Targeting & $\begin{array}{l}\text { Pct of funds granted to projects } \\
\text { adopting technology targets }\end{array}$ & 20 & 13.5 & 11.3 & 0.0 & 34.8 \\
Selectivity & $\begin{array}{l}\text { Pct of funds deliverable after } \\
\text { project evaluation by experts }\end{array}$ & 20 & 72.9 & 20.1 & 20.1 & 100.0 \\
\hline
\end{tabular}


trait is the fact that they offer knowledge-intensive services that can help firms adapt their cognitive capacity and overcome some major lock-ins. The support to the activities of intermediaries is compatible with an evolutionary approach to innovation, as these organisations are supposed to enhance firms' cognitive capacity (Caloffi and Mariani, 2011; Klerkx and Leeuwis, 2009; Laranja et al., 2008).

The local development variable provides information on how much regional policymakers invest in large-scale, and usually negotiated, local development projects. Most of these projects are inspired by a traditional growth-pole philosophy (Florio, 1996), and target large firms that the regional government tries to attract or retain. More recent versions envisage more complex local development packages targeting large firms with their smaller subcontractors.

The three following variables consider operationalisation modes. The first one measures the percentage of funds allocated to interventions aimed at supporting university-industry and industrial collaborations (collaboration). A higher value of this variable may indicate the presence of policymakers adopting a systemic approach to industrial and innovation policy (Laranja et al., 2008). Indeed, this policymaker does not consider the individual companies as the unit of interventions, but she targets dyads or more complex agglomerations of relationships among different organisations, be they geographically close or not. Collaborations can be encouraged for $R \& D$ and innovation (thus interweaving with the first variable), as well as for other industrial goals including the promotion of filières. ${ }^{9}$ In recent years, this kind of approach has been strongly encouraged by the EU. However, it is interesting to understand how strongly, and heterogeneously, the systemic goal has been pursued by governments.

The second operationalisation variable measures the percentage of funds allocated to interventions targeting strategic technology fields (targeting). Especially in recent years, the EU has repeatedly emphasised the importance of promoting key KETs in order to facilitate the generation of technological externalities that can benefit various sectors of the economy (European Commission, 2012). A high incidence of this type of variable suggests the presence of policymakers using the lever of the strategic targeting to generate and disseminate high technological opportunity conditions, particularly in those areas where private incentives to invest are relatively low (Bresnahan and Trajtenberg, 1995). When these interventions are aimed at promoting the adoption or the application of KETs to more traditional sectors, the policymakers try to help firms break the lock-ins that can affect them, and encourage processes of reorientation of these sectors.

Finally, the selectivity operationalisation variable refers to the evaluation mode of projects submitted for funding. It refers to the percentage of funds delivered after project evaluation by a commission of experts or, much less frequently, after having engaged in negotiation procedures involving the beneficiary and the regional government (versus the situation where funds are automatically, or semi-automatically, granted to applicant firms). This variable reveals that the regional government is trying to extract information from the private sector (e.g., on innovative projects, on promising technological fields and their possible industrial applications or on promising markets) that can then be used not only to select the best projects among the applicants, but also to fine-tune the design of subsequent policies and, possibly, to inform the choice of future policy targets (Eickelpasch and Fritsch, 2005). When this information is entered into a policy cycle, there may be a case of strategic interaction between policymakers and private agents in the sense stated by Rodrik (2004).

When performing a cluster analysis, there are some important methodological choices to make regarding: (i) the most appropriate way to aggregate the observations within a certain 
number of groups; (ii) the metric to use in order to measure the similarity/dissimilarity (i.e., the distance) between observations and between groups and (iii) the number of groups that it is desirable and appropriate to obtain (Kaufman and Rousseeuw, 1990).

Since clusters are just subsets of a same dataset, clustering methods can be classified according to whether the subsets are fuzzy or crisp (hard). All the most popular methods for cluster analysis perform crisp clustering, which assign units only to one cluster so that all subsets are mutually exclusive. It is easy to figure out situations where the boundaries between several clusters are not clear-cut and the crisp assignment of a unit to a given class represents a bit of a stretch. ${ }^{10}$ Under these circumstances, fuzzy clustering can represent an interesting alternative, since it allows the units to belong to several clusters at the same time but with different degrees of membership (Dunn, 1974). ${ }^{11}$

Analytical fuzzy-clustering algorithms are non-hierarchical and are often based on the optimisation of a $c$-means objective function (Bezdek, 1981). As usual with non-hierarchical approaches, a particular number of clusters $K$ (with $K>1$ ) has to be assumed. Then, let $N$ denote a set of $p$-dimensional data points (the 20 Italian regions described by $p=6$ classification variables), let $f>1$ be the desired degree of fuzzification (conventionally set at 2 for the reasons explained in Pal and Bezdek, 1995) and $c_{k}$ the centroid of the $k$ th cluster. The membership value of unit $x_{\mathrm{i}}(i=1, \ldots, N)$ in cluster $j(j=1, \ldots, K)$ is the quantity of primary interest. It is given by

$$
m_{i j}=\left(\sum_{k=1}^{K}\left(\frac{d_{i j}}{d_{i k}}\right)^{\frac{2}{f-1}}\right)^{-1}
$$

where the numerator is the distance between the unit $x_{\mathrm{i}}$ and the centroid of cluster $j$, i.e., $d_{i j}=\left\|x_{i}-c_{j}\right\|$, while the denominator represents the distance between the unit $x_{\mathrm{i}}$ and the centroid of every possible cluster, i.e., $d_{i k}=\left\|x_{i}-c_{k}\right\|$. Note that $\sum_{j} m_{i j}=1$ and that the metric chosen to measure the distance between observations is the squared Euclidean norm.

For the calculation of $m_{i j}$, centroids are initially selected at random, then equation (1) is computed for every $j$ and each unit is assigned to the cluster with higher membership. Then, the centroids for each one of the previous crisp clusters are identified, and equation (1) is computed again using these new centroids. This procedure is repeated until centroids are stable.

The most critical decision regards the choice of an appropriate number of clusters. Given the limited number of observations under scrutiny here, it is sensible to hope for a relatively limited number of groups that highlight some general mixes of enterprise and innovation policy, but this number should not be too low. The methodological literature proposes for this evaluation a number of cluster validity indexes (Bezdek, 1981; Kaufman and Rousseeuw, 1990; Xie and Beni, 1991), based on which $K=2$ and $K=4$ come out to be the first-best and the second-best solution, respectively, in this application. ${ }^{12}$

\section{Regional policy mixes in Italy}

In order to appreciate the results of our analysis, it can be useful to examine the cluster centroids reported in Table 2. Centroids are artificial values that are not observed in the original data. Notwithstanding, their combination in each cluster reveals what characterises each policy mix.

In the presence of two clusters $(K=2)$, two ideal mixes can be clearly identified that differ in terms of proactivity. The first mix puts a lower emphasis on innovation and technology targeting. Individual firms are the main unit of intervention, and very little effort is put in 
Table 2. Cluster centroids.

\begin{tabular}{llllllll}
\hline$K$ & $\begin{array}{l}\text { Cluster } \\
\text { id }\end{array}$ & R\&D & Intermediaries & $\begin{array}{l}\text { Local } \\
\text { development }\end{array}$ & Collaboration & Targeting & Selectivity \\
\hline$K=2$ & 1 & 29.61 & 4.72 & 18.81 & 15.69 & 5.94 & 59.66 \\
& 2 & 66.73 & 12.32 & 1.99 & 36.16 & 20.00 & 83.43 \\
$K=4$ & 1 & 30.21 & 3.92 & 11.03 & 14.27 & 4.60 & 50.26 \\
& 2 & 19.35 & 0.94 & 48.72 & 11.72 & 5.72 & 82.26 \\
& 3 & 87.21 & 6.82 & 0.27 & 60.01 & 19.34 & 92.71 \\
& 4 & 60.79 & 13.75 & 1.62 & 29.17 & 19.86 & 80.46 \\
\hline
\end{tabular}

supporting intermediaries. The recourse to selective allocation procedures based on project evaluation is relatively limited. On the other hand, the main signal of proactivity coming from these policymakers is their propensity to engage in usually negotiated, large-scale local development projects inspired by the traditional approach of the growth poles.

From Table 3, where regions are attributed to clusters according to their highest $m_{i j}^{K=2}$ and (fourth column), one can easily notice that this minimal mix is mostly met in Southern Italy. The second policy mix, instead, leans much more towards innovation, the creation of intermediaries, the promotion of collaboration, technology targeting and selectivity, but much less towards large-scale local development projects. This mix, which is proactive in an evolutionary and systemic sense, is rather common in Northern Italian regions.

When fuzziness is taken into account, regions exhibit different degrees of membership in each cluster: while most of them tend to polarise into the two policy mixes described so far, others exhibit intermediate mixes (Table 3, columns 2 and 3). For example, Molise or Sardinia's membership in the less proactive cluster is more than $90 \%$, while Abruzzo's is just $65 \%$. This means that Abruzzo does not represent as well as Molise or Sardinia the policy mix described using the centroids of the first cluster and that, in several respects, its own policy mix is halfway between the minimal and the proactive, although closer to the former. Following a similar line of reasoning, the policy mix characterising the more proactive regions is very well embodied by Tuscany $(98 \%)$ or Marche $(93 \%)$, but much less by Veneto $(62 \%)$, whose mix is halfway between the proactive and the minimal.

With $K=4$, each of the two large clusters already identified is divided into two parts. According to the new centroids reported in Table 2, there are now two different policy mixes for each level of government proactivity and, as shown in Table 3 (columns 5, 6, 7 and 8), a membership graduation for each of these.

The relatively minimal policy mix met in Southern Italy can be now divided into twospecific sub-mixes. Both have in common a limited practice of technology targeting and a limited attention towards the creation of intermediaries and the promotion of firms' and university-industry collaborations. However, one of these sub-mixes (cluster 2) is characterised by a remarkable presence of large-scale local development projects inspired to the traditional idea of growth poles (see centroids of cluster 2), while the other one is not (cluster 1). The former sub-mix is met in the two large Southern regions of Campania $(96 \%$ membership) and Apulia (92\%), while the latter is well embodied by Molise (97\%) and Sardinia (70\%). Other Southern regions, such as Sicily and Calabria, occupy an intermediate position, and Calabria's mix also incorporates some elements of evolutionary inspiration. Such elements are remarkable also in two other regions of Central Italy, namely Lazio and Abruzzo, characterised by a prevalently minimal approach. 
Table 3. Degrees of membership with $K=2$ and $K=4$.

\begin{tabular}{|c|c|c|c|c|c|c|c|c|}
\hline \multirow[b]{2}{*}{ Region } & \multicolumn{3}{|c|}{$K=2$} & \multicolumn{5}{|c|}{$K=4$} \\
\hline & $m_{i 1}$ & $m_{i 2}$ & $\begin{array}{l}\text { Closest } \\
\text { crisp cluster }\end{array}$ & $m_{i 1}$ & $m_{i 2}$ & $m_{i 3}$ & $m_{i 4}$ & $\begin{array}{l}\text { Closest } \\
\text { crisp cluster }\end{array}$ \\
\hline Abruzzo & 0.65 & 0.35 & I & 0.46 & 0.13 & 0.09 & 0.32 & 1 \\
\hline Aosta Valley & 0.10 & 0.90 & 2 & 0.08 & 0.05 & 0.39 & 0.48 & 4 \\
\hline Apulia & 0.74 & 0.26 & I & 0.04 & 0.92 & 0.01 & 0.03 & 2 \\
\hline Basilicata & 0.78 & 0.22 & I & 0.65 & 0.15 & 0.07 & 0.13 & I \\
\hline Calabria & 0.81 & 0.19 & I & 0.41 & 0.21 & 0.07 & 0.31 & I \\
\hline Campania & 0.76 & 0.24 & I & 0.02 & 0.96 & 0.01 & 0.01 & 2 \\
\hline Emilia-Romagna & 0.18 & 0.82 & 2 & 0.11 & 0.06 & 0.14 & 0.69 & 4 \\
\hline Friuli-Venezia Giulia & 0.17 & 0.83 & 2 & 0.02 & 0.02 & 0.88 & 0.08 & 3 \\
\hline Lazio & 0.79 & 0.21 & I & 0.62 & 0.09 & 0.05 & 0.24 & 1 \\
\hline Liguria & 0.13 & 0.87 & 2 & 0.10 & 0.06 & 0.22 & 0.62 & 4 \\
\hline Lombardy & 0.20 & 0.80 & 2 & 0.03 & 0.02 & 0.86 & 0.09 & 3 \\
\hline Marche & 0.07 & 0.93 & 2 & 0.03 & 0.01 & 0.04 & 0.92 & 4 \\
\hline Molise & 0.94 & 0.06 & I & 0.97 & 0.02 & 0.00 & 0.01 & 1 \\
\hline Piedmont & 0.13 & 0.87 & 2 & 0.09 & 0.06 & 0.18 & 0.67 & 4 \\
\hline Sardinia & 0.91 & 0.09 & I & 0.70 & 0.19 & 0.03 & 0.08 & 1 \\
\hline Sicily & 0.83 & 0.17 & I & 0.58 & 0.18 & 0.07 & 0.17 & I \\
\hline Trento & 0.22 & 0.78 & 2 & 0.12 & 0.10 & 0.17 & 0.61 & 4 \\
\hline Tuscany & 0.02 & 0.98 & 2 & 0.05 & 0.03 & 0.14 & 0.78 & 4 \\
\hline Umbria & 0.20 & 0.80 & 2 & 0.08 & 0.04 & 0.06 & 0.82 & 4 \\
\hline Veneto & 0.38 & 0.62 & 2 & 0.29 & 0.08 & 0.15 & 0.48 & 4 \\
\hline
\end{tabular}

Also in the northern part of the country regional governments do not adopt a homogeneous policy mix, although, as mentioned previously, they share some common features that are typical of a proactive and innovation-oriented policymaker. Where policy mixes in northern Italy differ remarkably is with respect to how much they lean towards a systemic sub-mix based on the promotion of collaborations rather than towards an evolutionary sub-mix that privileges innovation intermediaries (see the centroids of clusters 3 and 4 in Table 2).

The prototypes of the evolutionary sub-mix are three typical 'Third Italy' regions (Bagnasco, 1977): Marche (92\%), Umbria (82\%) and Tuscany (78\%), but this is the prevalent approach also in Emilia-Romagna, Piedmont, Liguria and in the province of Trento. Contrary to what one might have figured out by reading the vast literature on industrial districts in Third Italy, no programmes take industrial districts as their specific target and emphasis on local development programmes is also very limited (see note 9). Finally, the prototypes of the systemic sub-mix are Friuli-Venezia Giulia (88\%) and Lombardy ( $86 \%$ ), one of the country's economic engines.

In order to comment on these results, it may be useful to visualise the correlation that exists between the degree of adoption of a proactive policy mix $\left(m_{i 2}^{K=2}\right)$ and the level of innovativeness of the regional environment, summarised by the Revealed Regional Summary Innovation Index (RRSII) measured immediately prior to the start of the programming period under scrutiny (Hollanders, 2006; Figure 1). Based on a simple idea of equilibrium between policy demand and supply, the most natural expectation is that the higher the innovativeness of local environment, the more policy mixes are leaned towards innovation promotion. 


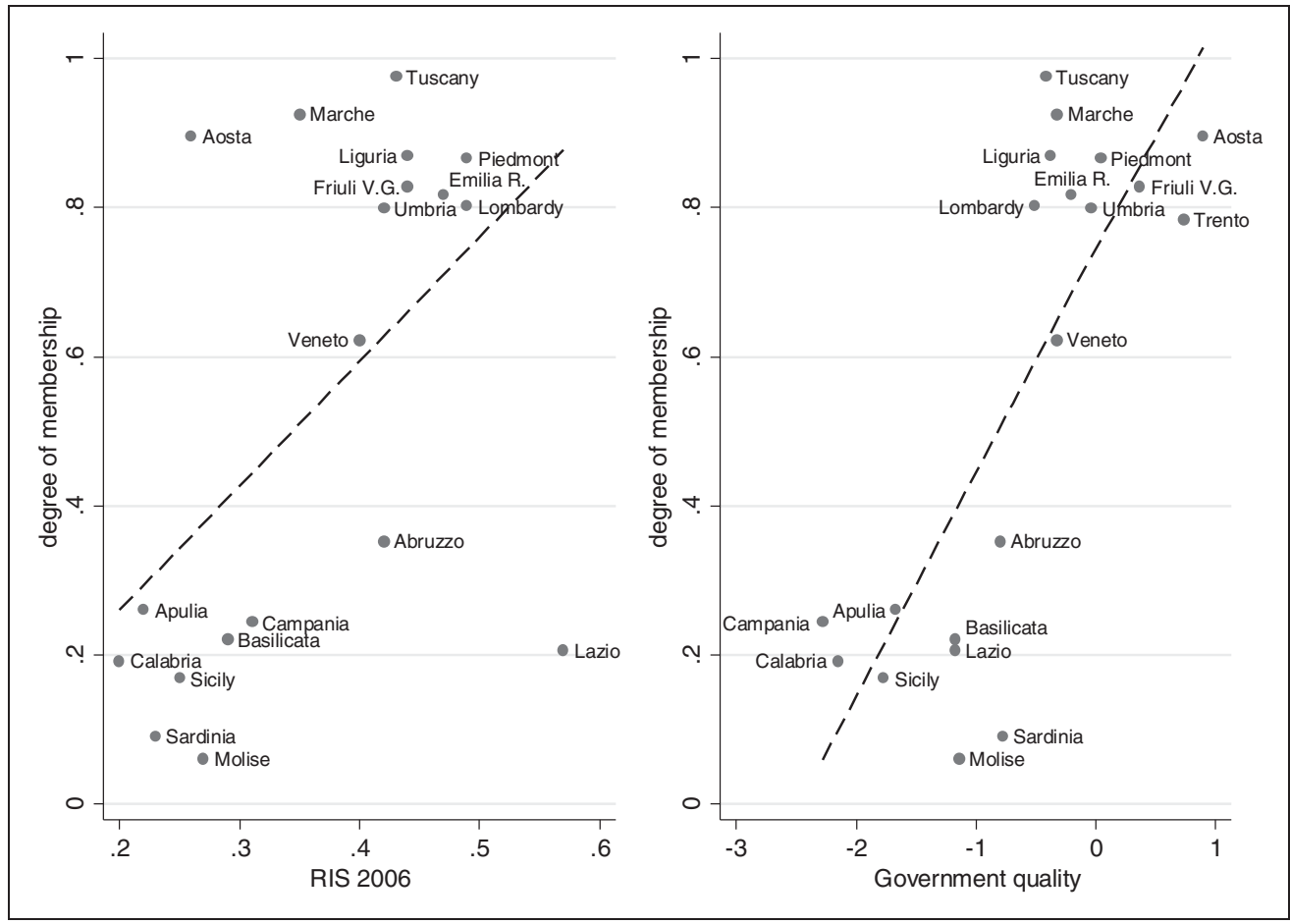

Figure I. Correlation between membership in the proactive policy mix $\left(m_{i 2}^{k=2}\right)$ and the levels of innovativeness and government quality of the regional environment.

Note: The source of the rank in the Revealed Regional Summary Innovation Index (RRSII) 2006 is Hollanders (2006); the index is unavailable for Trento. The source of the government quality index in 2010 is Charron et al. (2014).

Since a recent stream of literature is investigating the relationship between the quality of government at the regional level and regional economic or innovative performance (Rodríguez-Pose and Di Cataldo, 2014; Rodríguez-Pose and Garcilazo, 2015), it can be also interesting to view the correlation between the degree of adoption of the proactive policy mix and the quality level of regional government (European Quality of Government Index for the year 2010, Charron et al., 2014; Figure 1). As argued in the second section, one would expect that the higher the quality of government, the more such government will be likely to design a strategy to support structural change.

Figure 1 shows that the correlations that were hypothesised are actually positive. The policy mixes of most regions are very similar to the expectations, with Northern regions grouping top right, and Southern regions bottom left. However, the correlation between the quality of government and the degree of proactivity is stronger than the correlation between RRSII and proactivity. Indeed, the Spearman's rank correlation coefficient related to the right-hand graph of Figure 1 is 0.7 ( $p$ value 0.0005 ), which is larger than the 0.49 correlation related to the left-hand graph ( $p$ value 0.035 ).

It is evident from Figure 1 that some Northern regions, such as Marche, Tuscany or Aosta Valley, which do not rely on a better innovative environment than the other Northern regions, adopt notwithstanding a policy mix that is markedly proactive. Note that these regions are among those with decent government quality. A clear example of opposite sign is 
Table 4. Variable means in Convergence regions (Apulia, Calabria, Campania and Sicily) with and without national programmes for lagging-behind areas.

\begin{tabular}{llll}
\hline & & (b) Regional programmes & (c) Regional programmes \\
and National Operational \\
and National Operational \\
Pariable & (a) Regional & $\begin{array}{l}\text { Programmes where regional } \\
\text { allocation is specified }\end{array}$ & $\begin{array}{l}\text { Progional } \\
\text { or imputed }\end{array}$ \\
\hline R\&D supports & 23.7 & 40.7 & 40.7 \\
Intermediaries & 3.3 & 12.1 & 9.3 \\
Local development & 34.8 & 26.8 & 29.9 \\
Collaboration & 20.8 & 33.9 & 24.4 \\
Targeting & 7.3 & 16.8 & 8.3 \\
Selectivity & 75.2 & 80.5 & 85.9
\end{tabular}

Note: (a) Includes only regional programs. As only a few of the National Operational Programmes for Convergence regions declare a clear ex-ante allocation of resources to each region, (b) includes only National Operational Programmes with clear, ex-ante regional allocation and (c) includes all National Operational Programmes, also those where regional allocation was not pre-specified. If unspecified, allocation has been imputed to each region in the same proportion observed in programmes with pre-specified allocation.

that of Lazio, where the quality of government is rather low: in spite of the innovative regional environment, the policy mix is relatively minimal. This preliminary evidence seems to be consistent with the idea that quality of government is not irrelevant in explaining the policy mix actually adopted at the regional level.

The evidence on Southern regions suggests that governments of lagging regions where there is greater need to spend on innovation are less capable than those of stronger and more innovative regions to absorb and spend public funds devoted to innovation support (Milio, 2007; Trigilia, 2011). In addition, these governments have to reckon with a regional environment that is poorly innovative and that expresses weak demand for innovation supports of any kind (Navarro et al., 2009).

One must also remember that policies are the results of a complex multilevel framework (Flanagan et al., 2011; Lanahan and Feldman, 2015; Magro and Wilson, 2013; Matti et al., 2016). In particular, as suggested by the regional innovation paradox revisited by Hassink and Marques (2016), the effectiveness of regional innovation policy should be analysed in the context of a complex multi-scalar framework that includes also national and supra-national policies. This is particularly true for the Italian convergence regions, which are also the target of specific national programmes (PONs). Therefore, the fact that their regional policy mixes do not show such a high propensity to support R\&D and innovation projects might also be connected to the fact that these goals are pursued by the above mentioned PONs.

If these national programmes are added to our counts (Table 4), it is easy to verify that the overall average share of resources supporting innovation in convergence regions grows remarkably, and so does the share of resources devoted to intermediaries, collaborations and technologically targeted supports. This evidence suggests that, in convergence regions, several different policy mixes are in action: those of regional governments and that of national government delivering 'regional' policies. These mixes appear as complementary, although it is difficult to say to what extent this complementarity is intentional. ${ }^{13}$ 


\section{Final remarks}

The analysis performed in this article shows that there is remarkable heterogeneity in the policy mixes adopted by regional policymakers in Italy in support of enterprises and innovation. Some regions adopt a proactive role by focussing on innovation, collaborations and the creation of intermediaries, applying selective procedures and introducing technology targets, while others seem to be less ambitious as their focus is more on the horizontal support to generic investments with lower emphasis on innovation-driven structural change. While the first type of policymaker appears to lean towards regional reorientation and renewal, the second one seems to be more concerned with conservation.

A more attentive and detailed investigation discloses further heterogeneity within each one of these general policy mixes. Within the proactive mix we have identified an evolutionary and a systemic approach (Laranja et al., 2008) and assessed to what extent these approaches are taken in Italian regions. However, some forms of proactivity can be identified also in the group of policymakers who are less concerned with structural change, which are related to the promotion of large projects of local development. At this point, it would be interesting to understand which policy mixes work better in particular regional contexts. This is indeed a challenging goal, which however, would require a longer time horizon than that available now.

The fact that policy mixes leaning towards conservation are more likely to be met in weaker regional environments where the need for change is high recalls the paradox highlighted by Oughton et al. (2002). In fact, on the one hand, it can be hard for governments in weaker regions to stress innovation supports while the industrial base is not ready to absorb them (Capello and Lenzi, 2016; Navarro et al., 2009). On the other hand, as also stressed by the literature on government quality, the same regional governments possibly suffer from a number of weaknesses related to their policymaking ability, and therefore are less able (or willing) than higher quality ones to pursue a strategy to support structural change (Rodríguez-Pose and Garcilazo, 2015).

Based on these arguments, the primary goal of public policy in weaker regions should be that of raising the level of individual and firm capabilities. Obviously, this is a challenge that cannot be addressed by enterprise and innovation policy alone, if appropriate interventions for the enhancement of local human capital are not part of the package. In other words, a more complex, place-based approach (Barca et al., 2012) seems to be needed.

The picture changes slightly if, according to the suggestions of Hassink and Marques (2016), we do not consider the region as a closed entity and, in addition to regional programmes, we also consider the national action dedicated to the convergence regions. Although with some contradictions, national policy is characterised, in the observed period of time, by a strong emphasis on R\&D and technology targeting, combined with a selective approach. Therefore, the complementary action of central government on laggingbehind regions mitigates some of the differences among the different areas of the country.

\section{Acknowledgements}

Preliminary versions of this work have been presented at the XXXIII Conference of the Italian Regional Science Association (Rome, 13-15 September 2012), at the XXII edition of the Artimino Meetings on Local Development (Prato, 8-10 October 2012), at the XIII Workshop of the Italian Society of Industrial Economics and Policy (Milan, 5-6 February 2015) and 10th International Regional Innovation Policies Conference (Karlsruhe, 15-16 October 2015). The authors wish to thank the participants to these events for their valuable comments. Special thanks go to Ron Boschma (Utrecht University and CIRCLE) for his valuable suggestions. Remaining errors are, 
of course, our own. The authors are also grateful to Luca Rulli for his support in the collection of the data and in the construction of the database.

\section{Declaration of conflicting interests}

The author(s) declared no potential conflicts of interest with respect to the research, authorship, and/or publication of this article.

\section{Funding}

The author(s) received no financial support for the research, authorship, and/or publication of this article.

\section{Notes}

1. The label regional policies refer here to interventions designed and implemented by regional governments as a result of devolution or federalism, and not to national or supranational policies that aim to reduce territorial disparities and to promote convergence (see also Parr, 2015).

2. Although instruments in this approach are not tailored to regional policy, it has been noted that their application is likely to have territorial implications (e.g., Barca et al., 2012; Farole et al., 2011; Parr, 2015; Rodríguez-Pose, 2001).

3. See also Murphy et al. (2015) for the relationship between different forms of social capital and different policies.

4. From 2002 to 2013, the share of resources provided by the Regions on the total resources devoted to enterprise policy more than triples (from $10 \%$ in 2002 to $36 \%$ in 2013). In the Centre-North in particular, the percentage of regional spending covers $70 \%$ of the total funds for enterprise policy, while in Southern regions, many of which are eligible under the EU Convergence Objective, the weight of national resources is still predominant (Brancati, 2015).

5. For the case of Trentino-Alto Adige/Südtirol, the Autonomous Provinces of Bolzano and Trento have been considered and not the region, as provincial authorities are responsible for enterprise and innovation policies. However, Bolzano has been excluded because in that area policymakers do not provide a specific definition of resources allocated to each call (i.e., the resources are specified for the general axes of the ROP and not for the individual interventions).

6. The project Open Coesione (www.opencoesione.gov.it), recently implemented by the Ministry of Economic Development details the amount of resources spent by the Regions.

7. In particular, our search procedure was the following. We scrutinised the official bulletins of the Regions and of the State where all programme calls must be published by law. The official bulletins are published both in print and online, on the regions' websites. From such bulletins, we selected all calls related to enterprise and innovation programmes co-financed by ERDF or FAS. These calls include information about general objectives of the policy (e.g., supporting R\&D or generic firms' investments), instruments (e.g., subsidies or grants, and their amounts) and operationalisation modes (e.g., final beneficiaries of the policy, target sectors or technologies, features of the evaluation procedure). The completeness of the information collected from the bulletins is confirmed by the data that administrations presented in the Annual Reports of Execution 2013.

8. Common instruments are, for instance, loans, subsidies, grants. However, as shown by Laranja et al. (2008), the use such instruments may be compatible with almost all approaches to innovation policy (and, we would add, to enterprise policy). For this reason, we have not defined a variable related to the use of such instruments, but we have instead tried to detect the spread of more specific instruments such as intermediaries or local development 'packages', which can be peculiar to some policy approaches.

9. During the years 2000, regional policymakers have designed several interventions supporting collaborative projects implemented by organisations located in industrial districts, but most of these have never been implemented (Bellandi and Caloffi, 2016). More recently, regional and national policymakers have promoted many initiatives in support of districts, clusters and networks, but most of the interventions do not expressly require the geographical proximity 
between the participants. However, it has to be noted that regions provide funds to agents located within the regional boundaries, i.e., in a relatively small geographical area.

10. This stretch is usually revealed by the analysis of post-clustering silhouettes (Rousseeuw, 1987) or, more simply, by the fact that one or more classification variable exhibits a within-cluster standard deviation that is far too large or even some range overlap across clusters.

11. Although fuzzy clustering is a more flexible option than hard clustering, also the former is characterised by some degree of subjectivity with respect to the choice of the distance metrics, the number of desired clusters and, more in general, to the choice of the degree of fuzzification of the analysis. Our choices related to these aspects are documented and justified in the remainder of this section.

12. All computations were carried out using the recent 'fclust' package for R by Giordani and Ferraro (2014).

13. See Del Bo and Sirtori (2016) for an analysis on the relationship between EU structural funds and Italian public investment.

\section{References}

Adsera A, Boix C and Payne M (2003) Are you being served? Political accountability and quality of government. Journal of Law, Economics, and Organization 19(2): 445-490.

Bagnasco A (1977) Terza Italia. Problematiche dello sviluppo italiano. Bologna: Il Mulino.

Barca F, Mccann P and Rodríguez-Pose A (2012) The case for regional development intervention: Place-based versus place-neutral approaches. Journal of Regional Science 52(1): 134-152.

Bellandi M and Caloffi A (2016) Industrial policies in a Marshallian-based multilevel perspective. European Planning Studies 24(4): 687-703.

Bezdek JC (1981) Pattern Recognition with Fuzzy Objective Function Algorithm. New York: Plenum Press.

Boudeville JR (1966) Problems of Regional Economic Planning. Edinburgh: Edinburgh University Press.

Bresnahan TF and Trajtenberg M (1995) General purpose technologies 'Engines of Growth'? Journal of Econometrics 65(1): 83-108.

Bressers HTA and O'Toole LJ Jr (1998) The selection of policy instruments: A network-based perspective. Journal of Public Policy 18(03): 213-239.

Brancati R (ed.) (2015) Le strategie per la crescita. Imprese, mercati, stato. Roma: Meridiana Libri.

Branscomb LM and Florida R (1998) Challenges to technology policy. In: Branscomb LM and Keller $\mathrm{JH}$ (eds) Investing in Innovation: Creating a Research and Innovation Policy that Works. Cambridge, MA: MIT Press, pp. 462-495.

Caloffi A and Mariani M (2011) Shaping regional policy responses: The design of innovation poles. Policy Studies 32(4): 413-428.

Campbell JL (1998) Institutional analysis and the role of ideas in political economy. Theory and Society 27(3): 377-409.

Capello R and Lenzi C (2016) Relevance and utility of European Union research, technological development and innovation policies for a smart growth. Environment and Planning $C$ : Government and Policy 34(1): 52-72.

Chang HJ (2002) Breaking the mould: An institutionalist political economy alternative to the neoliberal theory of the market and the state. Cambridge Journal of Economics 26(5): 539-559.

Charron N, Dijkstra L and Lapuente V (2014) Regional governance matters: Quality of government within European Union member states. Regional Studies 48(1): 68-90.

Chiang JT (1998) High-technology targeting: Its modes' strategies and paradigms. Technology in Society 20(1): 1-23.

Coenen L, Asheim B, Bugge MM, et al. (2016) Advancing regional innovation systems: What does evolutionary economic geography bring to the policy table? Environment and Planning $C$ : Government and Policy. 0263774X16646583.

Cooke P, Heidenreich M and Braczyk HJ (eds) (2004) Regional Innovation Systems. The Role of Governance in a Globalized World. London: Routledge.

Del Bo CF and Sirtori E (2016) Additionality and regional public finance-evidence from Italy. Environment and Planning C: Government and Policy 34(5): 855-878. 
Dosi G, Freeman C, Nelson R, et al. (eds) (1988) Technical Change and Economic Theory. London: Pinter.

Dunn JC (1974) Well-separated clusters and optimal fuzzy partitions. Journal of Cybernetics 4(1): 95-104.

Eickelpasch A and Fritsch M (2005) Contests for cooperation - A new approach in German innovation policy. Research Policy 34(8): 1269-1282.

European Commission (2012) A European strategy for Key Enabling Technologies - A bridge to growth and jobs, $\operatorname{COM}(2012) 341$ final, European Commission, Bruxelles. Available at: http:// eur-lex.europa.eu/legal-content/EN/TXT/PDF/?uri=CELEX:52012DC0341\&from=EN (accessed 19 January 2017).

Farole T, Rodríguez-Pose A and Storper M (2011) Cohesion policy in the European Union: Growth, geography, institutions. Journal of Common Market Studies 49(5): 1089-1111.

Flanagan K, Uyarra E and Laranja M (2011) Reconceptualising the 'policy mix' for innovation. Research Policy 40(5): 702-713.

Florio M (1996) Large, entrepreneurship and regional development policy: 'growth poles' in the Mezzogiorno over 40 years. Entrepreneurship \& Regional Development 8(3): 263-295.

Foray D (2015) Smart specialisation. Opportunities and challenges for Regional Innovation Policy. Abingdon: Routledge.

Giddens A (1991) Modernity and Self-identity: Self and Society in the Late Modern Age. Stanford: Stanford University Press.

Giordani P and Ferraro MB (2014) fclust: Fuzzy clustering. R package version 1.0.1. Available at: http://CRAN.R-project.org/package=fclust (accessed 19 January 2017).

Grabas C (2014) Planning the economic miracle? Industrial policy in Italy between boom and crisis. In: Grabas C and Nützenadel A (eds) Industrial Policy in Europe After 1945. Wealth, Power and Economic Development in the Cold War. Basingstoke: Palgrave Macmillan, pp. 182-214.

Haapanen M, Lenihan H and Mariani M (2014) Government policy failure in public support for research and development. Policy Studies 35(6): 557-575.

Hassink M and Marques P (2016) The regional innovation paradox revisited. In: Hilpert U (ed.) Routledge Handbook of Politics and Technology. London: Routledge, pp. 120-131.

Hollanders H (2006) 2006 European Regional Innovation Scoreboard (2006 RIS). Brussels: European Commission.

Howells J (2006) Intermediation and the role of intermediaries in innovation. Research Policy 35(5): $715-728$.

Howlett M (1991) Policy instruments, policy styles, and policy implementation. Policy Studies Journal 19(2): $1-21$.

Howlett M (2004) Beyond good and evil in policy implementation: Instrument mixes, implementation styles, and second generation theories of policy instrument choice. Policy and Society 23(2): 1-17.

Howlett M and del Rio P (2015) The parameters of policy portfolios: Verticality and horizontality in design spaces and their consequences for policy mix formulation. Environment and Planning $C$ : Government and Policy 33(5): 1233-1245.

Johnson C (1982) MITI and the Japanese Miracle: The Growth of Industrial Policy: 1925-1975. Stanford: Stanford University Press.

Jones BD (2001) Politics and the Architecture of Choice: Bounded Rationality and Governance. Chicago: University of Chicago Press.

Jørgensen J and Mintzberg H (1987) Emergent strategy for public policy. Canadian Public Administration 30(2): 214-229.

Kaufman L and Rousseeuw PJ (1990) Finding Groups in Data: An Introduction to Cluster Analysis. New York: Wiley and Sons.

Klerkx L and Leeuwis C (2009) Establishment and embedding of innovation brokers at different innovation system levels: Insights from the Dutch agricultural sector. Technological Forecasting and Social Change 76(6): 849-860.

Lambooy JG and Boschma RA (2001) Evolutionary economics and regional policy. The Annals of Regional Science 35(1): 113-131. 
Lanahan L and Feldman MP (2015) Multilevel innovation policy mix: A closer look at state policies that augment the federal SBIR program. Research Policy 44(7): 1387-1402.

Laranja M, Uyarra E and Flanagan K (2008) Policies for science, technology and innovation: Translating rationales into regional policies in a multi-level setting. Research Policy 37(5): 823-835.

Linder SH and Peters BG (1989) Instruments of government: Perceptions and contexts. Journal of Public Policy 9(1): 35-58.

McCann E and Ward K (2013) A multi-disciplinary approach to policy transfer research: Geographies, assemblages, mobilities and mutations. Policy Studies 34(1): 2-18.

Magro E and Wilson JR (2013) Complex innovation policy systems: Towards an evaluation mix. Research Policy 42(9): 1647-1656.

Majone G (1989) Evidence, Argument, and Persuasion in the Policy Process. Yale: Yale University Press.

Mariani M, Caloffi A and Rulli L (2013) Le politiche per le imprese e l'innovazione in Italia: Le scelte delle regioni. In: IRES, IRPET, SRM, et al. (eds) La finanza territoriale in Italia. Rapporto 2013. Milano: Franco Angeli, pp. 191-208.

Matti C, Consoli D and Uyarra E (2016) Multi level policy mixes and industry emergence: The case of wind energy in Spain. Environment and Planning C: Government and Policy. 0263774X16663933.

Mazzucato M (2013) The Entrepreneurial State: Debunking Public vs. Private Sector Myths. London: Anthem Press.

Metcalfe JS (1994) Evolutionary economics and technology policy. The Economic Journal 104(425): 931-944.

Milio S (2007) Can administrative capacity explain differences in regional performances? Evidence from structural funds implementation in southern Italy. Regional Studies 41(4): 429-442.

Ministero dello Sviluppo Economico. (2012) Relazione annuale sugli interventi di sostegno alle attività economiche e produttive. Roma: MISE.

Morgan K (2007) The learning region: Institutions, innovation and regional renewal. Regional Studies 41(1): 147-159.

Morgan K (2016) Nurturing novelty: Regional innovation policy in the age of smart specialization. Environment and Planning C: Government and Policy. 0263774X16645106.

Murphy L, Huggins R and Thompson P (2015) Social capital and innovation: A comparative analysis of regional policies. Environment and Planning C: Government and Policy 34(6): 1025-1057.

Nauwelaers C and Wintjes R (eds) (2003) Innovation Policy in Europe: Measurement and Strategy. London: Edward Elgar Publishing.

Navarro M, Gibaja JJ, Bilbao-Osorio B, et al. (2009) Patterns of innovation in EU-25 regions: A typology and policy recommendations. Environment and Planning C: Government and Policy 27(5): 815-840.

Nelson RR and Winter SG (1982) An Evolutionary Theory of Economic Change. Cambridge, MA: Harvard University Press.

North DC (1990) Institutions, Institutional Change and Economic Performance. New York: Cambridge University Press.

OECD. (2011) Regions and Innovation Policy. Paris: OECD.

Oughton C, Landabaso M and Morgan K (2002) The regional innovation paradox: Innovation policy and industrial policy. The Journal of Technology Transfer 27(1): 97-110.

Pack H and Saggi K (2006) Is there a case for industrial policy? A critical survey. The World Bank Research Observer 21(2): 267-297.

Painter J (2005) Governmentality and regional economic strategies. In: Hillier J and Rooksby E (eds) Habitus: A Sense of Place. Aldershot: Ashgate, pp. 131-157.

Pal NR and Bezdek JC (1995) On cluster validity for the fuzzy c-means model. IEEE Transactions on Fuzzy Systems 3(3): 370-379.

Parr JB (1999) Growth-pole strategies in regional economic planning: A retrospective view part 1. Origins and advocacy. Urban Studies 36(7): 1195-1215.

Parr JB (2015) Neglected aspects of regional policy: A retrospective view. Environment and Planning C: Government and Policy 33(2): 376-392. 
Peck J, Theodore N and Brenner N (2012) Neoliberalism resurgent? Market rule after the great recession. South Atlantic Quarterly 111(2): 265-288.

Peneder MR (2016) Competitiveness and industrial policy: From rationalities of failure towards the ability to evolve. Cambridge Journal of Economics. DOI: 10.1093/cje/bew025.

Perroux F (1955) Note sur la notion de pôle de croissance. Economie Appliquée 8: 307-320.

Pigou AC (1912) Wealth and Welfare. London: Macmillan.

Polverari L (2013) Policy rhetoric versus political reality: Has the Italian state given up on the Mezzogiorno? Regional \& Federal Studies 23(5): 571-590.

Rodríguez-Pose A (2001) Is R\&D investment in lagging areas of Europe worthwhile? Theory and empirical evidence. Papers in Regional Science 80: 275-295.

Rodríguez-Pose A and Di Cataldo M (2014) Quality of government and innovative performance in the regions of Europe. Journal of Economic Geography 15(4): 673-706.

Rodríguez-Pose A and Garcilazo E (2015) Quality of government and the returns of investment: Examining the impact of cohesion expenditure in European regions. Regional Studies 49(8): 1274-1290.

Rodrik D (2004) Industrial policy for the twenty-first century. KSG Working Paper No. RWP04-047.

Rolfo S and Calabrese G (2003) Traditional SMEs and innovation: The role of the industrial policy in Italy. Entrepreneurship \& Regional Development 15(3): 253-271.

Rousseeuw PJ (1987) Silhouettes: A graphical aid to the interpretation and validation of cluster analysis. Journal of Computational and Applied Mathematics 20: 53-65.

Samuelson PA (1947) Foundations of Economic Analysis. Cambridge: Cambridge University Press.

Stiglitz JE and Lin LY (2013) The Industrial Policy Revolution I: The Role of Government Beyond Ideology. New York: Palgrave Macmillan.

Trigilia C (2011) Perché non si è sciolto il nodo del Mezzogiorno? Un problema di sociologia economica. Stato e Mercato 31(1): 41-76.

Uyarra E (2010) What is evolutionary about 'regional systems of innovation'? Implications for regional policy. Journal of Evolutionary Economics 20(1): 115-137.

Weiss L (1998) The Myth of the Powerless State. Ithaca: Cornell University Press.

Woolthuis RK, Lankhuizen N and Gilsing V (2005) A system failure framework for innovation policy design. Technovation 25(6): 609-619.

Xie XL and Beni G (1991) A validity measure for fuzzy clustering. IEEE Transactions on Pattern Analysis and Machine Intelligence 13(8): 841-847.

Annalisa Caloffi is an Assistant Professor at the Department of Economics and Business, University of Padova. Her main research interests include industrial and innovation policies, innovation networks, and industrial districts and clusters. She has been involved in a number of international research projects on innovation policies and clusters, including EU-funded Research Framework projects, as well as in several projects funded by national and regional agencies. Her works have been presented in several conferences worldwide and published in peer-reviewed journals, books and other national and international outlets.

Marco Mariani has earned his $\mathrm{PhD}$ from the University of Florence, Italy. He is now an economist at IRPET (Regional Institute for the Economic Planning of Tuscany). His main research interests lie in the area of applied industrial and business economics and include: R\&D and innovation, small-and medium-sized enterprises and firm demography. In parallel, he is strongly concerned with enterprise and innovation policies and interested in quantitative programme evaluation methodologies. His most recent contributions are in the area of small-business policy analysis and evaluation. His current interests also encompass active labour market policies, public procurement and cultural economics. 